\title{
Global Responses to the COVID-19 Pandemic
}

\author{
John Steven Ott ${ }^{1} \cdot$ Frances L. Edwards ${ }^{2} \cdot$ Pitima Boonyarak $^{3}$
}

Accepted: 24 November 2021 / Published online: 27 December 2021

(C) The Author(s), under exclusive licence to Springer Science+Business Media, LLC, part of Springer Nature 2021

How well have governments and NGOs responded to the COVID-19 pandemic? It remains too early in the disease's progression to assess the outcomes of the different approaches taken in countries and states/provinces around the globe. "Unquestionably, this pandemic has become an enormous challenge to governments' decisionmaking processes and has created deep community and political divisions and strife in some countries" (Edwards \& Ott, 2021, 880, citing Rothwell \& Makridis, 2020). Governments everywhere have had to learn "on the fly" with limited data to support their decisions and frequently have had to learn "on the fly" with limited data to support their decisions and frequently when faced with overwhelming mis-information and conspiracy theories. Government officials world-wide have had to make decisions that require populations and business establishments to change their behaviors although faced with "considerable disagreement about which measures best represent 'successful' government interventions" (Edwards \& Ott, 2021, 880). And, few government institutions are designed, structured or inclined to make policy decisions in this type of environment where "surprise management" is required (Farazmand, 2010).

Two of the co-editors of this special issue of Public Organization Review (Edwards and Ott) also co-edited a 2021 special issue of The International Journal of Public Administration (44[11,12]) that was published on-line in July 2021 on essentially the same topic. We decided to move swiftly to initiate this special issue in Public Organization Review because the pandemic situation and circumstances were changing rapidly around the world. We knew that many things would be outdated by the time that the IJPA special issue was published in summer-fall 2021. So, a call for proposals for this special issue was issued in December 2020, draft manuscripts were received in May 2021, and near-final manuscripts were collected in early August 2021.

John Steven Ott

jsott@cppa.utah.edu

1 Department of Political Science/Public Administration Program, University of Utah, Salt Lake City, UT, USA

2 Public Administration Program, San Jose State University, San Jose, CA, USA

3 Pitima Boonyarak, City of Calgary, Alberta, Canada 
Obviously, the decision was the right one. Almost all of the articles in the IJPA special issue had been researched and written before vaccines had become widely available; vaccination rates of highly vulnerable populations soared; new infections, hospitalizations, and deaths in most advanced countries rose and then plummeted; the Delta Variant was only beginning to be identified and had spread only minimally beyond India; and, many cities, states/provinces, and countries were mandating masks indoors and/or had ordered "lockdowns." For example, the IJPA article, "Nonprofit Capacity to Manage Hurricane-Pandemic Threat: Local and National and Perspectives on Resilience during COVID-19" that focuses on hurricane and pandemic- ravaged New Orleans, Louisiana (Hutton et al., 2021) was written before Louisiana developed into a COVID-19 epicenter and before Hurricane Ida struck with devastating force in August 2021.

As this Special Issue of POR goes to production, months have elapsed between the research reported and the evolving situation across the world. Austria is seeing riots over lockdowns for unvaccinated residents (Eddy, 2021). Other European nations are experiencing COVID-19 surges that are causing concern at the WHO (BBC, 2021), and China's "zero COVID" policy is impacting the global economy (Bloomberg News, 2021). The divided US (Bump, 2021) has introduced vaccines for children from 5 to 17 years old, and boosters for adults (HHS.gov, 2021), while the more unified Iranian population has four internally-created vaccines, and under the new leadership of President Raeisi has achieved 80\% vaccination (Farazmand, personal communication, November 24, 2021).

It is evident from the studies included in this special issue that many governments have demonstrated some agility, flexibility and innovation during the pandemic (Aoki, 2021; Christensen \& Laegred, 2020; Conte, 2020), but most local, state/provincial, and national governments have lagged, resisted change, and have not learned well from previous experiences including the combined hurricane-pandemic in New Orleans and the SARS epidemic in China (Ma \& Christiansen, 2021).

As studies in this special issue show, governments have been utilizing a variety of approaches to form and implement COVID-19 policies, including top down, bottom up, and collaborative partnerships. For example, China has relied heavily on a top down approach as the government imposed strong quarantine policies and health restrictions (Ma \& Christiansen, 2021). Poland provides an example of a bottom up approach wherein municipalities played a front-line role in implementing policies in response to the pandemic (Kańdula \& Przbylska, 2021). And, Iran and Jordan have adopted hybrid approaches that have included both top down and bottom up strategies. These two governments have used their control powers as well as collaborating with nongovernmental actors to ensure that services reach community residents (Alshoubaki \& Harris, 2021; Maleki, 2021).

This special issue of POR will be far from the final word on the COVID-19 pandemic. Many turns and twists in the path lie ahead (Telenti et al., 2021). More variants will emerge, and some variants will likely be able to overcome protection provided by existing vaccines (Bollinger \& Ray, 2021). New vaccines will become available. Rates of new infections, hospitalizations, and deaths will rise and fall. Circumstances and responses will continue to vary widely among countries (Serikbayeva et al., 2021). The gap in disease incidence between countries and areas 
within countries continues to widen with devastatingly unequal impacts on certain populations (Chung \& Yi, 2021; Christensen, 2021).

What should we expect in the next couple of years? How well will governments and NGOs respond? How well will they learn from experience (Jang et al., 2021)? Will community members comply with government policies to achieve "herd immunity" and the elimination of hosts for new variants (Murray \& Piot, 2021)? Will the pendulum swing toward required vaccinations and/or masks, or will "the right of individual freedom" continue to trump public health in some countries? The articles in this special issue address many of these questions. Several of the articles identify varied, innovative approaches to public policy and practices by governments and communities when confronted with the pandemic. On the other hand, the articles mostly tend to describe and analyze government shortcomings and inflexibility when confronted with the pandemic crisis. In too many cases, the lessons have not been learned well enough (Wallace-Wells, 2021). Too many government responses have been ineffective - and in some cases counter-productive - for reasons of political polarization (Altiparmakis et al., 2021; Rothwell \& Makridis, 2020), disinformation (Brennen et al., 2020; Kee, 2021), widely spread conspiracy theories (Douglas, 2021; Islam et al., 2021), and alternative realities (Pearson, 2021).

We have learned some important lessons from the global management experience with the COVID-19 pandemic as is documented in the articles in this special issue. One of the potentially beneficial outcomes has been the realization of the wide range of skills that effective public servants will need to face the challenges of the twentyfirst century. Professors and mentors of new public administrators should help their students adapt their skills and acquire the knowledge to operate in this polarized and distrustful world, where many citizens trust faceless social media "influencers" more than their government agencies. This new world will require public administrators to learn to collaborate across sectoral lines and with new stakeholders, from the National Guard to NGOs to for-profit companies in order to deliver essential services like food, housing, health and mental health services, vaccinations and education. The only way to resolve the communication divide is to expand the cultural competency of public administrators who must interface with residents of multiple ethnicities and belief structures. Only when the messengers speak in ways that their community can accept will government agencies become the trusted voice over the noise of the social media "influencers." The lack of trust can be life threatening, for example when community members choose to follow a social media post rather than the fire department's evacuation direction, and drive into the fire lines.

We have also learned that public agencies must create equity in service delivery, working toward the removal of barriers for all so that the distribution of resources becomes not only equitable but also just. Pop up vaccination centers at grocery stores and filling stations in low income communities, free Wi-Fi hot spots for elementary school students, and distribution of food boxes to the elderly by community members are examples of asking not what someone deserves, but what she needs. Representing the underrepresented has become another crucial role of public administrators. For years we have told our students that all of our community members should be treated equally, but COVID-19 has shown us that we must advocate for those without a voice. Nursing home patients proved to be especially vulnerable in 
COVID-19 as they were during Hurricanes Katrina and Ida. Staff members abandoned them to go care for their own families, leaving only public agencies to recognize the needs and attempt to find ways to meet them.

Balancing public health needs with economic realities became an impossible task for public health officials. How can the death of a person be balanced against the death of a family's livelihood? How do you explain scientific evidence-based policymaking to people who have lost their homes and jobs due to lockdowns? How does government balance who benefits and who pays?

We may be able to create some things that are good out of trying to respond to something so disruptive as COVID-19. For example, NGO-governmental partnerships that transcend a crisis and become part of the emergency management cycle of preparedness, response, recovery and mitigation in a community could be a longterm benefit. Natural hazards will continue to happen more frequently and with more intensity, seasonally and cyclically. Using lessons such as the impacts of climate change to deal with other endemic threats from the long running COVID challenge may strengthen our communities for the long-term challenges. As public administrators we must learn to balance the economy with children's education; rebuild safe housing while balancing the needs of elderly homeowners for economic stability; manage the trade-offs between societal safety and the price of individual freedom; respect religious beliefs while maintaining community security. The authors of the articles in this Special Issue have posed these questions and have also offered some answers, some glimmers of hope for more compassionate, equitable and balanced public policymaking.

Brief overviews of each article follow.

"Comparing SARS and COVID-19: Challenges of Governance Capacity and Legitimacy," by Liang Ma, Renmin University of China; \& Tom Christensen, University of Oslo.

China's handling of its responses to pandemics improved from SARS in 2003 to COVID-19 but also demonstrated persistent inertia and lack of learning in governance capacity. For example, the source of the SARS virus was suppressed which undermined the government's capacity to respond to the pandemic in many ways. In contrast, the government was far better prepared to fight COVID-19 through improved expertise, increased coordination, and better transparency. Although the COVID-19 response was delayed initially by the government, it quickly implemented strong measures including quarantines, restrictions on movement by people, and other health controls.

"Contingency Planning and Early Crisis Management: Italy and the COVID-19 Pandemic," by Paula Mattei, University of Milan.

This comparative analysis of Italy's decentralized health care system's preparedness for and anticipatory planning to deal with the COVID-19 pandemic revealed that four regions differed widely. The causes were varied, but confusion about regional vs. national responsibility for medical supplies and equipment was prevalent during the early months of the pandemic. In a highly decentralized governance system such as Italy's, joint actions and collabora- 
tion in planning and implementation are crucial between levels of government and with key outside actors.

"Financial Instruments Used by Polish Municipalities in Response to the First Wave of COVID-19," by Slawomira Kańdula, Poznan University of Economics; \& Joanna Przybylska, University of Economics and Business.

Municipalities are necessarily in the front line of the fight against the consequences of the pandemic. Municipalities in Poland struggled in their attempts to initiate anti-crisis programs and financial instruments in the early months of the pandemic because of the negative economic and budgetary consequences of the pandemic. This study revealed that the loss of revenue and the increase in expenses because of COVID-19 were not as large as expected. Few urban or rural municipalities used tax exemptions, and rural municipalities used nontax revenue instruments less than urban municipalities.

“Jordan's Public Policy Response to COVID-19 Pandemic: Insight and Policy Analysis," by Wa'ed. Alshoubaki, University of Jordan; \& Michael Harris, Tennessee State University.

Jordan is a developing country. Despite scarce resources, poor economic conditions, and social vulnerability, Jordan's unitary system of government created social protection policies to assist people who lost their jobs or whose work was suspended due to COVID-19. Adoption of a streamlined interagency coordination mechanism across government departments, the private sector, and NGOs was a key strategy in the country's early success. Jordan has also used "hard power" to control the COVID-19, including early lockdowns and imposing sanctions on violations that threaten the lives of others.

"Social Policy Responses to COVID-19 - Challenges of Helping Vulnerable Groups," by Tom Christensen, University of Oslo.

The lack of targeted social policies towards Norway's most vulnerable populations - groups that are at a disadvantage because of the lack of social resources including particularly children, youth, and the aging -- during the pandemic have caused social isolation and the absence of daily supports. Government has had to respond to three pandemic-caused challenges simultaneously: public health, the economic effects, and social and psychological impacts. In these areas of challenge, socially disadvantaged populations have not been well protected from the virus, and assistance to mitigate the social effects has been sluggish.

"Iran and COVID-19: A Bottom-up, Faith-Driven, Citizen-Supported Response," by Ali Maleki, Sharif University of Technology.

Studies of crisis and emergency management have recently expanded from exclusively top-down in focus to include the roles of nongovernmental actors, stakeholders and citizens in bottom-up responses. Iran's response to the COVID-19 pandemic relied significantly on citizen groups and community 
mobilization despite heavy sanctions and limited resources. Iran's primarily faith-driven, collaborative, civic engagement response has served hospitals, elderly homes, cemeteries and infected families despite personal risk to the volunteers.

"Direct Management of COVID-19 Pandemic at National and Subnational Level: The Case of the Northwest Amazon Basin Nations," by Gabriel Weber, ESSCA; Ignazio Cabras, Northumbria University; Paola Ometto, California State University, San Marcos; \& Ana Maria Peredo, University of Victoria.

Remote, poverty-plagued, indigenous communities in the Western Amazon area of Brazil, Columbia and Peru have suffered heavily from the COVID19 pandemic. The suffering and disruption of life routines in these communities have been intensified by long-standing government neglect, marginalization, discrimination, land dispossession, social exclusion, cultural differences, and high levels of malnutrition. Healthcare services in these three countries have been negatively impacted by neoliberal public policies and practices, and government shortcomings and failures at both the national and local levels, which have had disproportionate impacts in the Western Amazon area.

"The Impact of Culture in Crisis Management - How Did Young Japanese and Germans Perceive the Corona Crisis Management of their Governments?", by Véronique Goehlich, \& Luca Kampe, Hochschule Pforzheim.

Culture has had a major impact on government crisis management during the coronavirus crisis in Germany and Japan. The cultural dimensions of this study provide a framework that enables a comparison between these cultures and their effects on government actions. The findings suggest that cultural principles can affect crisis management in practice. However, values and ideals have been significantly modified by this crisis. The framework presented in this article permits the identification of cultural and crisis barriers and thus solutions can be found to operate more efficiently, equitably and effectively in crises.

"Public Trust in Government and Compliance with Policy during the COVID19 Pandemic: Empirical Evidence from Vietnam," by Vu Thanh Van, Academy of Journalism and Communication.

In Vietnam, there has been a significant positive correlation between accessible, trustworthy communication and public trust in government, and a significantly moderate positive correlation between public trust in government and compliance with government's policies in response to the COVID-19 pandemic. Effective policy communication and implementation of COVID19 responses have led to public trust in government, and trust in government has resulted in citizens' support for and compliance with government policies. 
"Use of Social Media and Citizens' Initiatives for Crisis Management: An Analysis of COVID-19 Crisis in Bangladesh," by (I DO NOT HAVE THE AUTHOR'S NAME OR AFFILIATION)

Factors such as the development of trust, opportunities for digital transactions, the existence of moderators, and easily available platforms to connect citizen-driven groups in order to successfully coordinate actors and provide crucial supplies including, for example blood, plasma, and medical equipment have proven to be highly successful in Bangladesh. These citizen-driven groups started to use social media - mainly Facebook - to reduce their vulnerability by establishing connections and coordinating efforts among people and groups. This study analyses the activities of different groups attempting to coordinate gaps in services and to deal with the scarcity of resources, and factors that may have contributed to successful efforts.

"Smart Working as Institutional Response during COVID-19 Pandemic: A Comparative Analysis among the Employees of Two Italian Public Research Organizations," by Marco Cellini, Italian National Research Council.

The social distancing and isolation that COVID-19 has required has caused public and private organizations in Italy to institute new workforce forms, including Smart Working. Smart Working is a structured way to regulate the relationship between organizations and their workers during times of changing circumstances. Smart Working increases competitiveness and facilitates worklife balance. This study compares the effects of implementing Smart Working on the quantity and quality of work in two large public research organizations.

Acknowledgements The co-editors of this special issue wish to acknowledge the invaluable engaged collaboration, participation, and contributions made by Professor Ali Farazmand, Editor-in-Chief of Public Organization Review.

\section{References}

Alshoubaki, W., Harris, M. (2021) "Joran's Public policy Response to COVID-19 Pandemic: Insight and Policy Analysis." Included in this special issue of Public Organization Review.

Altiparmakis, A., Bojar, A., Brouard, S., Foucault, M., Kriesi, H., \& Nadeau, R. (2021). Pandemic politics: Policy evaluations of government responses to COVID-19. West European Politics, 44(5,6), 1159-1179.

Aoki, N. (2021). Stay-at-home request or order? A study of the regulation of individual behavior during a pandemic crisis in Japan. International Journal of Public Administration, 44(11,12), 885-895.

BBC News. (2021). Covid: WHO says it is very worried about Europe surge. BBC News. Retrieved November 24, 2021 from https://www.bbc.com/news/world-europe-59358074

Bloomberg News. (2021). China is more dedicated than ever to COVID zero as it battles delta. Bloomberg News. Retrieved November 24, 2021 from https://www.bloomberg.com/news/articles/2021-1122/china-more-dedicated-than-ever-tocovid-zero-as-it-battles-delta 
Bollinger, R., \& Ray, S. (2021). New variants of coronavirus: What you should know. Johns Hopkins Medicine: Health. Retrieved from https://www.hopkinsmedicine.org/health/conditions-and-disea ses/coronavirus/a-new-strain-ofcoronavirus-what-you-should-know. Accessed 12 Aug 2021.

Brennen, S., Simon, F. M., Howard, P. N., \& Nielsen, R. K. (2020). Types, sources, and claims of COVID-19 misinformation. Oxford University Factsheet. Oxford, UK: University of Oxford.

Bump, P. (2021). Vaccine politics only worsened the partisan divide in covid-19 deaths. The Washington Post. Retrieved November 24, 2021 from https://www.washingtonpost.com/politics/2021/11/08/ vaccine-politics-only-worsened-partisandivide-covid-19-deaths/

Christensen, T. (2021). Social policy responses to COVID-19: Challenges of helping vulnerable groups. Included in this special issue of Public Organization Review.

Christensen, T., \& Laegreid, P. (2020). Balancing governance capacity and legitimacy: How the Norwegian government handled the COVID-19 crisis as a high performer. Public Administration Review, 80(5), 774-779.

Chung, E., \& Yi, J. (2021). Pandemic priorities: The impact of South Korea's COVID-19 policies on vulnerable populations. International Journal of Public Administration, 44(11,12), 1028-1038.

Conte, R. (2020). Increasing your remote teams' productivity with Smart Working. Forbes. Retrieved August 16, 2021, from https://www.forbes.com/sites/theyec/2020/05/19/increasing-your-remoteteams-productivity-with-smart-working/?sh=aa3137d3d8a1

Douglas, K. M. (2021). COVID-19 conspiracy theories. Sage Perspectives. Retrieved August 12, 2021, from https://doi.org/10.1177/1368430220982068.

Eddy, M. (2021). Thousands in Austria protest virus lockdown and vaccine mandate. New York Times, November 23. Retrieved November 23, 2021, from https://www.nytimes.com/2021/11/20/world/ europe/austria-lockdown-vaccine-mandatecovid.html

Edwards, F. L., \& Ott, J. S. (2021). Governments' responses to the COVID-19 pandemic. International Journal of Public Administration, 44(11,12), 879-884.

Farazmand, A. (2010). Crisis and emergency management: Theory and practice. Taylor \& Francis.

HHS.gov. (2021). COVID-19 vaccine distribution: the process. US Department of Health and Human Services. Retrieved November 24, 2021 from https://www.hhs.gov/coronavirus/covid-19-vaccines/ distribution/index.html

Hutton, N. S., Mumford, S. W., Saitgalina, M., Yusuf, J.-E., Diaz, R., \& Kiefer, J. J. (2021). Nonprofit capacity to manage hurricane-pandemic threat: Local and national perspectives on resilience during COVID-19. International Journal of Public Administration, 44(11,12), 984-993.

Islam, M. S., Kamal, A-H. M., Kabir, A., Southern, D. L., Khan, S. H., Murshid, S. M. M., Sarkar, T., Shamin, S., Das, S., Roy, T., Harun, M. G. D., Chughtai, A. A., Homaira, N., \& Seale, H. (2021). COVID-19 vaccine rumors and conspiracy theories: The need for cognitive inoculation against misinformation to improve vaccine adherence. Plos One. https://doi.org/10.1177/1368430220982068.

Jang, H. S., Dicke, L. A., Keyes, L., Shi, Y., \& Kim, J. (2021). Responding to the needs of the homeless in the COVID-19 pandemic: A review of adaptations in 20 major U.S. cities. International Journal of Public Administration, 44(11,12), 1005-1017.

Kańdula, S., \& Przybylska, J. (2021). Financial Instruments Used by Polish Municipalities in Response to the First Wave of COVID-19. Included in this special issue of Public Organization Review.

Kee, L. K., (2021). Fighting the spread of COVID-19 misinformation. News. Boston, Mass.: T.H. Chan School of Public Health.

Ma, L., \& Christiansen, T. (2021). Comparing SARS and COVID-19: Challenges of governance capacity and legitimacy. Included in this special issue of Public Organization Review.

Maleki, A. (2021). Iran and COVID-19: A bottom-up, faith-driven, citizen-supported response. Public Organization Review. https://doi.org/10.1007/s11115-021-00567-9.

Murray, C. J. S., \& Piot, P. (2021). The potential future of the COVID-19 pandemic: Will SARS-CoV-2 become a recurrent seasonal infection? JAMA Viewpoint, 325(13), 1249-1250.

Pearson, M. (2021). There's no such thing as 'alternative facts'. 5 ways to spot misinformation and stop sharing it online. The Conversation. Retrieved August 12, 2021, from https://theconvers ation.com/theres-no-such-thing-as-alternative-facts-5-ways-to-spot-misinformation-and-stop-shari ng-it-online-152894

Rothwell, J., \& Makridis, C. (2020). Politics is wrecking America's pandemic response. Up front. Brookings Institution.

Serikbayeva, B., Abdulla, K., \& Oskenbayev, Y. (2021). State capacity in responding to COVID-19. International Journal of Public Administration, 44(11,12), 920-930. 
Telenti, A., Arvin, A., Corey, L., Corti, D., Diamond, M. S., Garcia-Sastre, A., Garry, R. F., Holmes, E. C., Pang, P., \& Virgin, H. W. (2021). After the pandemic: Perspectives on the future trajectory of COVID-19. Nature. https://doi.org/10.1038/s41586-021-03792-w.

Wallace-Wells, D. (2021). How the west lost COVID. How did so many rich countries get it so wrong? New York Magazine/Intelligencer. Retrieved from https://nymag.com/intelligencer/2021/03/howthe-west-lost-covid-19.html. Accessed 16 Aug 2021.

Publisher's Note Springer Nature remains neutral with regard to jurisdictional claims in published maps and institutional affiliations.

John Steven Ott is Professor Emeritus of Political Science/Public Administration and former Dean of the College of Social and Behavioral Science at the University of Utah. Ott has taught and written extensively about organization theory and organizational behavior in the public and nonprofit sectors

Frances L. Edwards MUP, PhD is the Deputy Director of the National Transportation Security Center at the Mineta Transportation Institute, and a professor and director of the Master of Public Administration program at San Jose State University. She is the editor or co-author of four books and numerous journal articles and book chapters.

Pitima Boonyarak Ph.D. is a Business and Policy Strategist for the City of Calgary, Alberta, Canada. 